\title{
Carotid Intima-Media Thickness Is Associated with Increased Androgens in Adolescents and Young Adults with Classical Congenital Adrenal Hyperplasia
}

\author{
Mimi S. Kim a, d, e Anh Dao-Tran ${ }^{a}$ Elana Davidowitz ${ }^{a}$ Teresa Tseng $^{\text {a }}$ \\ Vicente Gilsanz ${ }^{b}$, d, e Anna Ryabets-Lienharda, ${ }^{d}$ Eugene Nguyen ${ }^{c}$ \\ Mitchell E. Geffner ${ }^{a}$ d, e \\ ${ }^{a}$ Division of Endocrinology, Diabetes, and Metabolism, b Department of Pediatric Radiology, and \\ 'Division of Hospital Medicine, Children's Hospital Los Angeles, ${ }^{d}$ Keck School of Medicine of the University of

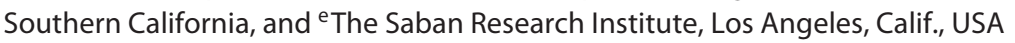

\section{Key Words}

Congenital adrenal hyperplasia $\cdot 21$-hydroxylase .

21-hydroxylase deficiency - Carotid wall thickness .

Intima-media thickness - Cardiovascular disease .

Cardiovascular risk factors - Cardiovascular risk in children

\begin{abstract}
Background/Aims: Youth with congenital adrenal hyperplasia (CAH) due to 21-hydroxylase deficiency develop cardiovascular disease (CVD) risk factors of obesity and hypertension. Carotid intima-media thickness (CIMT), a marker of CVD risk, is increased in CAH young adults. We examined CIMT and its relationship with androgens and obesity in adolescents/young adults with $\mathrm{CAH}$. Methods: Twenty $\mathrm{CAH}$ subjects (age $16 \pm 3.3$ years, $50 \%$ female) and 20 matched controls were studied cross-sectionally. Eight additional obese patients with $\mathrm{CAH}$ were included in within-group comparisons. CIMT by high-resolution ultrasound, androgens, anthropometry, bone age (BA), and metabolic/inflammatory markers were assessed. Results: Within the $\mathrm{CAH}$ group, CIMT correlated with 17-hydroxyprogesterone $(r=$
\end{abstract}

\section{KARGER}

E-Mail karger@karger.com

www.karger.com/hrp
$0.48, p<0.05)$ and androstenedione $(r=0.46, p<0.05)$, and was greater in obese subjects. CIMT was greater in $\mathrm{CAH}$ males than females, but similar among $\mathrm{CAH}$ females with advanced $\mathrm{BA}, \mathrm{CAH}$ males with normal $\mathrm{BA}$, and control males. There was no difference in CIMT between CAH and controls, although high-density lipoprotein was inversely correlated with CIMT in both groups. Conclusion: CIMT is associated with increased androgens in $\mathrm{CAH}$ adolescents and young adults, with loss of sex differences in $\mathrm{CAH}$ females with excess androgen exposure. Our findings highlight the importance of hormonal control for CVD prevention in CAH.

(c) 2016 S. Karger AG, Basel

\section{Introduction}

Carotid intima-media thickness (CIMT) is a well-established marker of early, subclinical atherosclerotic change that corresponds to risk for coronary artery disease and stroke $[1,2]$. Increased CIMT is associated with male sex, adiposity, and body mass index (BMI) in children and teens, as well as with highly sensitive C-reactive protein
(C) 2016 S. Karger AG, Basel

1663-2818/16/0854-0242\$39.50/0
Mimi S. Kim

Children's Hospital Los Angeles

4650 Sunset Boulevard, Mailstop \#61

Los Angeles, CA 90027 (USA)

E-Mail mskim@chla.usc.edu 
(hs-CRP) in children as young as 7 years old $[3,4]$. Children with classical congenital adrenal hyperplasia $(\mathrm{CAH})$ due to 21-hydroxylase deficiency have an increased risk for obesity and hyperandrogenism [5-8], and nonobese adolescents with CAH have demonstrated an increased prevalence of insulin resistance and increased blood pressure similar to what is seen in obese adolescents without $\mathrm{CAH}$ [6]. Young adults with $\mathrm{CAH}$ have increased CIMT, in association with decreased insulin sensitivity, compared to matched controls [9]. Current studies also suggest that polycystic ovarian syndrome (PCOS), another hyperandrogenic condition in women that is associated with cardiovascular disease risk, is also independently associated with increased CIMT $[10,11]$. However, CIMT results vary in existing studies of individuals with $\mathrm{CAH}$ [12-14].

As the relationship between CAH and CIMT remains unclear, we set out to study CIMT in adolescents and young adults with classical $\mathrm{CAH}$ due to 21-hydroxylase deficiency and investigate correlations with sex, anthropometric measurements, and circulating levels of androgens, lipids, and inflammatory markers. We hypothesized that CAH subjects with bone age (BA) advancement, as a marker of excessive and/or prolonged androgen exposure, would have increased CIMT compared to CAH subjects without BA advancement. Furthermore, we hypothesized that subjects with $\mathrm{CAH}$ would have increased CIMT compared to matched controls without CAH and that their CIMT would have positive associations with obesity and androgen levels.

\section{Materials and Methods}

\section{Study Participants}

Individuals with classical CAH due to 21-hydroxylase deficiency and controls were recruited from the Pediatric Endocrinology and General Pediatrics clinics at Children's Hospital Los Angeles (CHLA), respectively, and rigorously matched for age, sex, pubertal stage, ethnicity, BMI, and waist-to-height ratio (WHtR). An additional 8 unmatched, obese $\mathrm{CAH}$ subjects were included for within-CAH group analyses. Inclusion criteria for $\mathrm{CAH}$ subjects included a previous diagnosis of classical CAH due to 21-hydroxylase deficiency based on biochemical and/or genetic testing, and age $\geq 12$ years. Controls were healthy other than being overweight or obese, and were $\geq 12$ years old. Exclusion criteria included age $<12$ years, other chronic medical conditions, and inability to participate in a clinical evaluation, blood draw, and carotid artery imaging at CHLA.

Anthropometric measurements of height, weight, BMI, WHtR, and waist circumference, along with blood pressure (average of three separate readings), were obtained. BMI was categorized using Centers for Disease Control guidelines, with $\geq 85$ th percentile defined as overweight and $\geq 95$ th percentile as obese. For youth aged $<18$ years, prehypertension was defined as systolic blood pressure (SBP) or diastolic blood pressure (DBP) between the 90th and 94th percentile and hypertension as SBP or DBP $\geq 95$ th percentile [15]. For young adults, prehypertension was defined as SBP between 120 and $140 \mathrm{~mm} \mathrm{Hg}$ or DBP between 80 and $90 \mathrm{~mm} \mathrm{Hg}$, and hypertension as SBP $\geq 140 \mathrm{~mm} \mathrm{Hg}$ or DBP $\geq 90 \mathrm{~mm} \mathrm{Hg}$ [16]. A waist circumference $>90$ th percentile for age was considered increased [17]. Pertinent medical history and family history of cardiovascular disease (CVD) risk factors (early myocardial infarction, smoking, type 2 diabetes, hypertension, hyperlipidemia, and obesity) were also obtained.

The CHLA Committee on Clinical Investigations (Institutional Review Board) approved the research protocol. Patients who were 18 years old or older and parents of participating children gave written informed consent, and all minors gave assent.

Imaging

Doppler ultrasounds of the arterial wall of the left common carotid artery were performed by the same technician, with measurements taken $1 \mathrm{~cm}$ proximal to the carotid bifurcation using a highresolution 15L8 MHz linear-array transducer (Acuson Sequoia 512; Siemens Medical Solutions USA, Inc., Malvern, Pa., USA), during three separate complete cardiac cycles. CIMT measurements were determined using automated, computerized edge detection software (Siemens Medical Solutions USA, Inc., 2002, v.1.0) to depict the narrowest and widest vessel diameters in the systolic and diastolic frames of each cycle, as previously described [18]. The average of three systolic and three diastolic frames was used for analysis.

A radiograph of the left hand was used to determine BA using the Greulich-Pyle method [19] and read in a blinded fashion by a single pediatric endocrinologist (M.S.K.). BA was defined as advanced when greater than the subject's chronological age by 1 year or more. BA was obtained at the time of the study visit, or within several months of the visit if taken for clinical purposes. The individuals who had completed growth at the time of the study visit had their BA X-rays reviewed for earlier full maturity as adolescents.

\section{Laboratory Analytes}

Participants had blood drawn at our Clinical Trial Unit after an overnight (12-hour) fast and prior to routine morning medications in the CAH group. The last glucocorticoid dose was taken the evening before in all CAH patients. Fasting analytes included: glucose, insulin, and lipids [total cholesterol, high-density lipoprotein cholesterol (HDL), low-density lipoprotein cholesterol (LDL), and triglycerides] (measured by radioimmunoassay); leptin (measured by electrochemiluminescence); 17-hydroxyprogesterone (17OHP), androstenedione, and total testosterone (measured by liquid chromatography and tandem mass spectrometry); free testosterone (calculated); and sex hormone-binding globulin (SHBG), dehydroepiandrosterone sulfate (DHEAS) and inflammatory markers (plasminogen activator inhibitor-1 antigen, hs-CRP, and homocysteine; measured by immunoassay). All analytes were measured at Quest Diagnostics Nichols Institute (San Juan Capistrano, Calif., USA). Insulin sensitivity was quantified by the homeostatic model assessment of insulin resistance [HOMA-IR = (insulin $\mu \mathrm{U} / \mathrm{ml}) \times($ glucose $\mathrm{mmol} / \mathrm{l}) / 22.5]$. Disease control was categorized based on the 17-OHP level, with $\mathrm{CAH}$ individuals considered suppressed if 17-OHP was $<100 \mathrm{ng} / \mathrm{dl}$, in acceptable control if between 100 and $1,200 \mathrm{ng} / \mathrm{dl}$, in intermediate control if $1,200-5,000 \mathrm{ng} / \mathrm{dl}$, and in poor control if $>5,000 \mathrm{ng} / \mathrm{dl}[6]$. 
Table 1. Clinical characteristics of adolescents and young adults with CAH due to 21-hydroxylase deficiency and controls

\begin{tabular}{|c|c|c|c|}
\hline & $\mathrm{CAH}(\mathrm{n}=20)$ & Control $(n=20)$ & $\mathrm{p}$ value \\
\hline Females & 10 & 10 & $\mathrm{~N} / \mathrm{A}$ \\
\hline Age, years & $16 \pm 3.3$ & $16.5 \pm 2.4$ & 0.56 \\
\hline Weight, kg & $65.3 \pm 18.4$ & $70.2 \pm 23.2$ & 0.47 \\
\hline Height, $\mathrm{cm}$ & $158 \pm 11.3$ & $163.5 \pm 9.75$ & 0.11 \\
\hline Height SDS & $-0.88 \pm 1.19$ & $-0.22 \pm 1.38$ & 0.12 \\
\hline BMI & $26.5 \pm 8.7$ & $26.2 \pm 8.6$ & 0.93 \\
\hline BMI SDS & $0.81 \pm 1.17$ & $0.73 \pm 1.18$ & 0.82 \\
\hline Body surface area, $\mathrm{m}^{2}$ & $1.68 \pm 0.26$ & $1.77 \pm 0.31$ & 0.30 \\
\hline Waist circumference, $\mathrm{cm}$ & $81.5 \pm 14.9$ & $83.5 \pm 16.5$ & 0.69 \\
\hline Waist-to-height ratio & $0.52 \pm 0.11$ & $0.51 \pm 0.10$ & 0.78 \\
\hline Heart rate, beats/min & $74.3 \pm 15.8$ & $70.6 \pm 9.8$ & 0.42 \\
\hline $\mathrm{SBP}, \mathrm{mm} \mathrm{Hg}$ & $113 \pm 12.6$ & $113.5 \pm 10.2$ & 0.89 \\
\hline $\mathrm{DBP}, \mathrm{mm} \mathrm{Hg}$ & $62 \pm 11.3$ & $61.4 \pm 8.3$ & 0.86 \\
\hline Total cholesterol, mg/dl & $158.7 \pm 32.4$ & $149.9 \pm 28.0$ & 0.36 \\
\hline $\mathrm{LDL}, \mathrm{mg} / \mathrm{dl}$ & $86.3 \pm 19.7$ & $89.1 \pm 27.3$ & 0.71 \\
\hline Triglycerides, mg/dl & $74.3 \pm 33.9$ & $119.8 \pm 94.9$ & 0.02 \\
\hline $\mathrm{HDL}, \mathrm{mg} / \mathrm{dl}$ & $55.1 \pm 12.4$ & $47.0 \pm 10.8$ & 0.03 \\
\hline \multicolumn{4}{|c|}{ CAH group including the additional 8 obese CAH subjects $(n=28)$} \\
\hline \multicolumn{4}{|c|}{ Glucocorticoid dose in hydrocortisone } \\
\hline Fludrocortisone dose, mg/day & \multicolumn{3}{|l|}{$0.1 \pm 0.06$} \\
\hline 17-OHP, ng/dl & \multicolumn{3}{|l|}{$5,677.3 \pm 7,803.9$} \\
\hline Androstenedione, ng/dl & \multicolumn{3}{|c|}{$198.7 \pm 200.4$} \\
\hline DHEAS (females/males), $\mu \mathrm{g} / \mathrm{dl}$ & \multicolumn{3}{|c|}{$27.9 \pm 39.9 / 45.2 \pm 26.2$} \\
\hline Total testosterone (females/males), ng/dl & \multicolumn{3}{|c|}{$21.4 \pm 14.2 / 412.4 \pm 225.6$} \\
\hline Free testosterone (females/males), $\mathrm{pg} / \mathrm{ml}$ & \multicolumn{3}{|c|}{$4.1 \pm 3.7 / 63.6 \pm 34.8$} \\
\hline
\end{tabular}

Figures are means \pm SD unless indicated otherwise.

Statistical Analysis

SPSS software (SPSS Inc., Chicago, Ill., USA) was used for all statistical analyses. Parametric and nonparametric tests were employed to test significance. Paired t tests were used to compare cases with controls, while Pearson and Spearman correlations were used to test variable relationships. All statistical assumptions were investigated before assessment. The criterion for significance was $\alpha=0.05$ in all analyses. Power calculations were performed using $\mathrm{G}^{*}$ Power 3.1 [20]. Results are shown as mean \pm standard deviation.

\section{Results}

Baseline characteristics of CAH subjects and controls are shown in table 1. Twenty adolescent and young adult subjects previously diagnosed with classical CAH were recruited along with 20 controls. The $20 \mathrm{CAH}$ subjects (aged $16 \pm 3.3$ years, range 12.9-24.1, 50\% female, and
$35 \%$ obese) did not differ from controls (aged 16.5 \pm 2.4 years, range $12.1-20.5,50 \%$ female, and $30 \%$ obese) with regard to age, sex, pubertal stage, and BMI. Tanner stage ranged from IV to $\mathrm{V}$ for all subjects, and matching for Tanner stage by sex was done. Young adult was defined as being 18 years and older; in our cohort, there were 3 young adults with $\mathrm{CAH}$, and 1 young adult without $\mathrm{CAH}$.

We observed no difference between $\mathrm{CAH}$ subjects and controls with regard to baseline SBP, DBP, total cholesterol, and LDL. However, there were differences in triglycerides and HDL between CAH subjects and controls, with $\mathrm{CAH}$ having lower triglycerides and higher HDL ( $\mathrm{p}=0.02$ and $\mathrm{p}=0.03$, respectively).

Including the additional 8 obese CAH subjects $(\mathrm{n}=$ 28 , 4 young adults, aged $15.6 \pm 3.2$ years, range $11.8-24.1$, $54 \%$ female, and $50 \%$ obese), the CAH group consisted of $71 \%$ having the salt-wasting form and $29 \%$ having the 


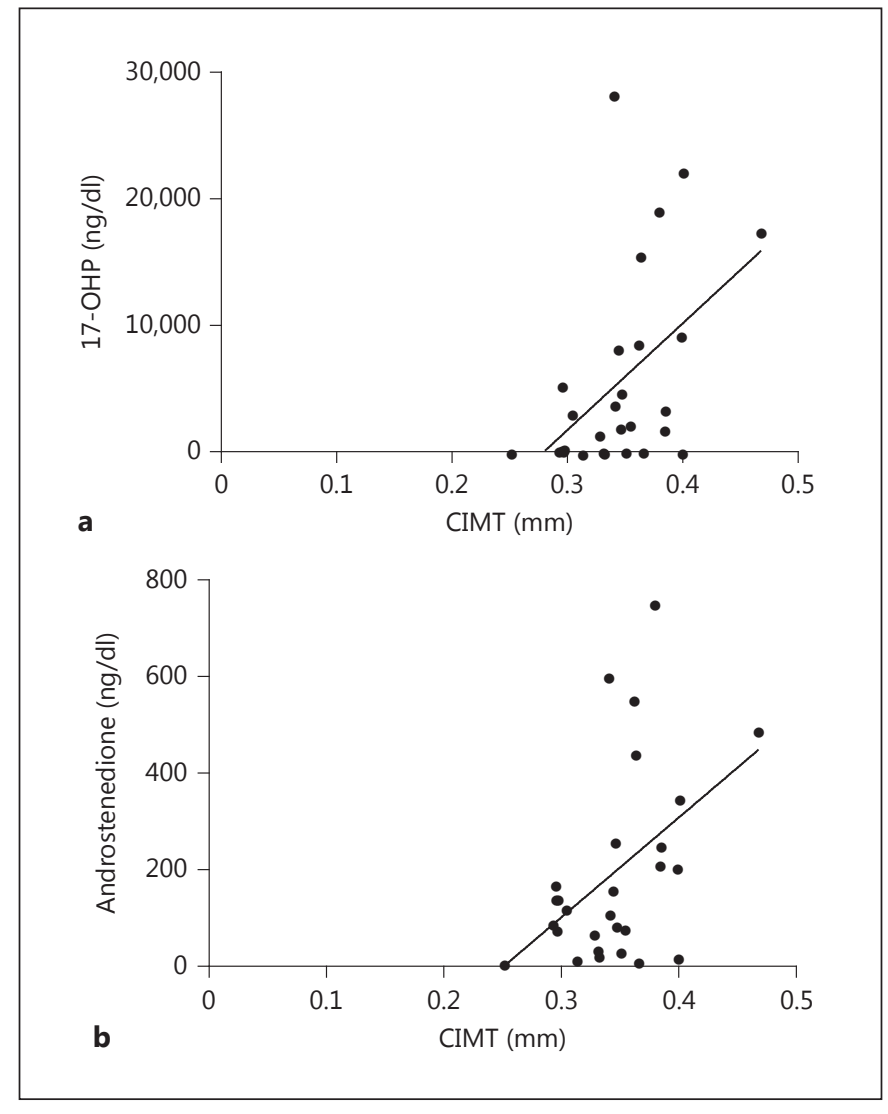

Fig. 1. CIMT in adolescents and young adults with classical CAH due to 21-hydroxylase deficiency. a CIMT correlated positively with $17-\mathrm{OHP}(\mathrm{R}=0.48 ; \mathrm{p}<0.05)$. b CIMT correlated positively with androstenedione $(\mathrm{R}=0.46 ; \mathrm{p}<0.05)$.

simple virilizing form, as determined by genotype for $90.5 \%$ of the cohort; 6 subjects with multiple heterozygous mutations identified on polymerase chain reaction analysis were classified based on clinical phenotype. Of the $28 \mathrm{CAH}$ subjects, 19 were taking hydrocortisone, 8 were taking dexamethasone, and 1 was taking prednisone for their daily glucocorticoid replacement. Twentyfour of the 28 subjects were taking fludrocortisone $(0.1 \pm$ $0.06 \mathrm{mg} /$ day) for mineralocorticoid replacement. As assessed by cross-sectional 17-OHP levels, 4 CAH subjects were considered suppressed, 7 were in acceptable control, 8 were in intermediate control, and 9 were in poor control.

The main finding of the study was that, within the CAH group $(\mathrm{n}=28)$, mean CIMT $(0.35 \pm 0.05 \mathrm{~mm})$ correlated positively with serum levels of 17-OHP (172.0 \pm $236.4 \mathrm{nmol} / \mathrm{l}, \mathrm{r}=0.48, \mathrm{p}<0.05$; fig. 1a) and androstenedione $(6.93 \pm 6.99 \mathrm{nmol} / \mathrm{l}, \mathrm{r}=0.46, \mathrm{p}<0.05$; fig. 1b). Fe-

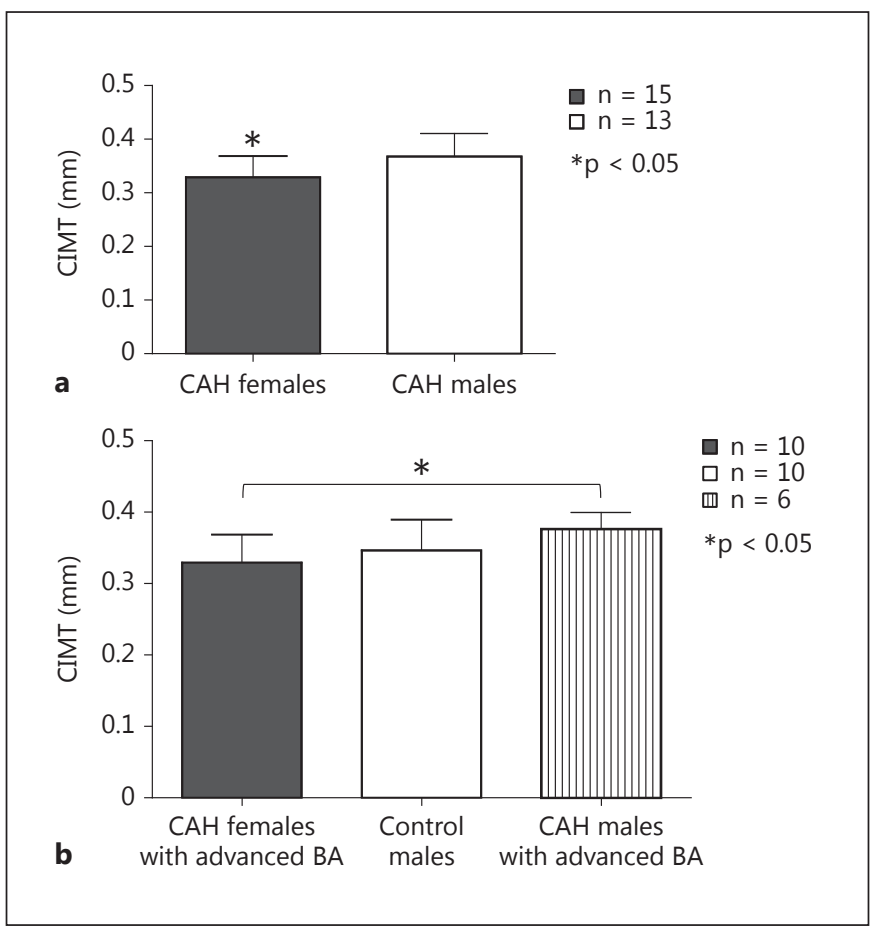

Fig. 2. Sex differences in CIMT in adolescent and young adult females with $\mathrm{CAH}$ and males with and without CAH. a CIMT in all adolescent and young adult females with CAH compared to CIMT in all males with CAH. CIMT is lower in the females compared to the males $(\mathrm{p}<0.05)$. $\mathbf{b}$ CIMT between CAH females with advanced $\mathrm{BA}$, control males, and $\mathrm{CAH}$ males with advanced $\mathrm{BA}$. There is no difference between the $\mathrm{CAH}$ females with advanced BA and control males $(\mathrm{p}=0.68)$. The CAH females with advanced BA have a lower CIMT than the CAH males with advanced BA $(\mathrm{p}<0.05)$.

males with CAH had a lower CIMT than males with $\mathrm{CAH}$ $(0.33 \pm 0.04$ vs. $0.37 \pm 0.04 \mathrm{~mm}, \mathrm{p}<0.05$; fig. $2 \mathrm{a})$. Females with CAH did not have elevated androgens overall; 2 had mildly elevated androstenedione (115 and $118 \%$ of normal) and 1 of these females additionally had elevated testosterone (130\% of normal). However, the subgroup of females with CAH who had an advanced BA $(n=10)$ also had a CIMT similar to control males $(n=10)$, rendering a sex-based difference in CIMT insignificant between these two groups $(0.34 \pm 0.04$ vs. $0.35 \pm 0.04 \mathrm{~mm}, \mathrm{p}=0.68$; fig. 2b). There were also no sex-based differences in CIMT when comparing the $\mathrm{CAH}$ females who have advanced $\mathrm{BA}$ with $\mathrm{CAH}$ males who did not have an advanced BA $(\mathrm{n}=7 ; 0.34 \pm 0.04$ vs. $0.36 \pm 0.05 \mathrm{~mm}, \mathrm{p}=0.35)$ or with all CAH males ( $\mathrm{n}=13,0.37 \pm 0.04 \mathrm{~mm}, \mathrm{p}=0.11)$. However, $\mathrm{CAH}$ males with advanced BA $(\mathrm{n}=6)$ still had a higher CIMT than the CAH females with advanced BA $(0.38 \pm 0.02$ vs. $0.34 \pm 0.04 \mathrm{~mm}, \mathrm{p}<0.05$; fig. $2 \mathrm{~b})$. 


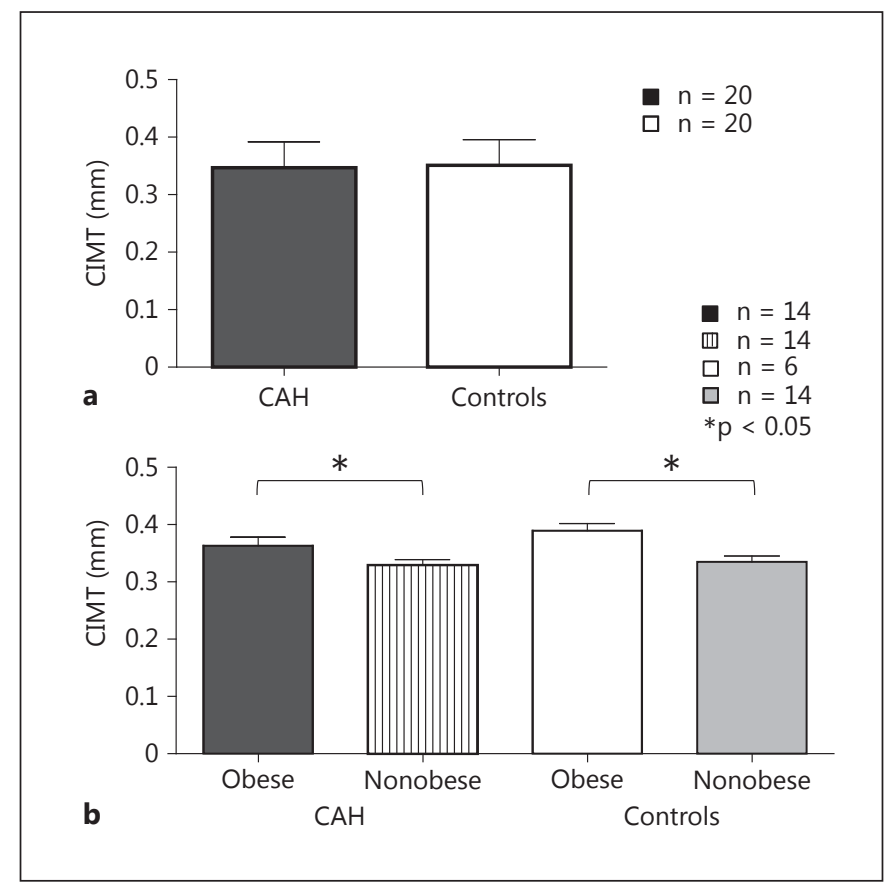

Fig. 3. CIMT in adolescents and young adults with $\mathrm{CAH}$ and in controls. a CIMT in CAH compared to controls. There is no difference between the two groups $(\mathrm{p}=0.76)$. $\mathbf{b}$ CIMT of obese and nonobese individuals with and without CAH. CIMT was increased in obese individuals compared with nonobese, for both $\mathrm{CAH}$ and control groups $(\mathrm{p}<0.05)$.

There was no difference in CIMT between CAH $(\mathrm{n}=$ $20)$ and matched controls $(n=20 ; 0.34 \pm 0.04$ vs. $0.35 \pm$ $0.04 \mathrm{~mm}, \mathrm{p}=0.5$; fig. 3a). HDL was inversely associated with CIMT in both CAH $(1.38 \pm 0.31 \mathrm{mmol} / \mathrm{l}, \mathrm{r}=-0.4$, $\mathrm{p}<0.05)$ and control $(1.22 \pm 0.28 \mathrm{mmol} / \mathrm{l}, \mathrm{r}=-0.47, \mathrm{p}<$ $0.05)$ groups. Otherwise, there were no correlations between CIMT and waist circumference, WHtR, BMI percentile, HOMA-IR, leptin, family history of CVD risk factors, SHBG, total cholesterol, LDL, triglycerides, triglyceride-to-HDL ratio, or inflammatory markers (plasminogen activator inhibitor-1, hs-CRP, and homocysteine) in either the CAH or control groups (data not shown). However, when including the additional 8 obese $\mathrm{CAH}$ subjects for a within-CAH group comparison, CIMT was significantly greater in obese CAH $(\mathrm{n}=14)$ than in nonobese CAH subjects $(\mathrm{n}=14,0.37 \pm 0.04$ vs. $0.33 \pm 0.04 \mathrm{~mm}, \mathrm{p}<0.05$; fig. $3 \mathrm{~b}$ ). CIMT was also greater in obese controls $(n=6)$ versus in nonobese controls ( $\mathrm{n}=14 ; 0.39 \pm 0.03$ vs. $0.33 \pm 0.04, \mathrm{p}<0.05$; fig. $3 \mathrm{~b})$. In the CAH group, CIMT did not correlate with DHEAS, total testosterone, or free testosterone. Also, there was no difference in CIMT between subjects with the salt-wasting versus simple virilizing forms of CAH. Lastly, there was no correlation between hydrocortisone equivalent dose and CIMT.

\section{Discussion}

Our study suggests that in adolescents and young adults with $\mathrm{CAH}$, there are associations between androgens and CIMT, linking hyperandrogenism with subclinical atherosclerosis, an important emerging CVD risk factor. Known differences between the sexes exist in CIMT from puberty throughout adulthood, and ultimately, adult men have increased CVD events compared to women. The CIMT measurements in our CAH group showed the same sexual dimorphism (females: $0.33 \pm 0.04 \mathrm{~mm}$ vs. males: $0.37 \pm 0.04 \mathrm{~mm}, \mathrm{p}<0.05)$ seen in large normative studies (females: $0.38 \pm 0.04 \mathrm{~mm}$ vs. males: $0.39 \pm 0.04$ $\mathrm{mm}, \mathrm{p}<0.05$ ), although the ethnicity composition of our study cohorts differed [3]. Androgen excess could itself be a risk factor for CVD in women, with increased CIMT and an unfavorable overall CVD risk profile seen in hyperandrogenic women $[3,10,11,21]$. In our CAH group, adrenal androgens, 17-OHP, and advanced BA, as a marker of substantial and prolonged androgen exposure, directly correlated with CIMT in both sexes. Laboratory analytes were measured after an overnight fast and prior to morning glucocorticoid medication administration when adrenal androgen levels are potentially at their highest. This differed from the methodology of a previous study of CIMT in adolescents with CAH that found no relationship with 17-OHP and androstenedione in which analytes were measured in blood samples drawn following the administration of morning glucocorticoid medication [12]. We also found that accounting for advanced $\mathrm{BA}$ in $\mathrm{CAH}$ females eliminated sexual dimorphism in CIMT both within CAH and between CAH versus control groups. Significant associations between androgens and CIMT have yet to be reported in adolescents and young adults with hyperandrogenism due to $\mathrm{CAH}$. Our findings support the possibility that androgens may be contributing to the development of CVD risk.

Differences in CVD between men and women continue to fuel interest in the role of androgens in the development of CVD risk. It is well-established that men have earlier CVD manifestations than women in middle to late adulthood [22], but studies in men have failed to find a definitive link between higher androgen levels and CVD risk [23], with the exception of illicit androgen use for 
appearance/performance enhancement [24]. However, multiple associations exist between androgen excess and the development of an atherogenic lipid profile in hyperandrogenic women [25-27], as well as insulin resistance in adolescent girls and women $[28,29]$. In postmenopausal women, the risk of hypertension correlates positively with free testosterone and DHEAS, and inversely with SHBG [30]. Androgens have been shown to have both direct and indirect effects on CVD risk, interacting with the vascular endothelium to promote inflammation and oxidative stress [31], and indirectly increasing blood pressure via actions on the kidney [30]. Possible mechanisms can be derived from rodent models, where testosterone increases the production of reactive oxygen species via activation of cytosolic NADPH-oxidase subunit p47phox, reversing the protective effects of estrogen on vascular function in postmenopausal animals [32], and reduces endothelium-dependent vasorelaxation in a PCOS model [33]. Although CVD risk in PCOS has been more extensively studied compared to $\mathrm{CAH}$, the $\mathrm{CAH}$ model includes both sexes. Thus far, adolescents with $\mathrm{CAH}$ have been found to have evidence of vascular dysfunction, with reduced flow-mediated dilatation compared to controls [12]. Our study found greater CIMT in males with advanced BA, potentially demonstrating that the harmful effect of pathological hyperandrogenism on CIMT may be relevant for both males and females with $\mathrm{CAH}$.

We also found that CIMT was significantly greater in obese than in nonobese adolescents and young adults, in both $\mathrm{CAH}$ and control groups, supporting the established theory that obesity increases the risk of developing CVD. However, our group of largely adolescent $\mathrm{CAH}$ subjects did not have significantly different CIMT measurements compared to controls, consistent with another study of adolescents with CAH that used similar ultrasound methods and matched their subjects for age, sex, and BMI zscore [12]. Our findings in CAH, compared to a BMImatched cohort, suggest that individuals with classical CAH due to 21-hydroxylase deficiency may not develop subclinical atherosclerosis in adolescence. Nevertheless, since it is known that $\mathrm{CAH}$ confers a higher relative risk for obesity and adiposity in childhood and adolescence $[5,6,34]$, it remains concerning that obese $\mathrm{CAH}$ subjects exhibit higher CIMT than their nonobese counterparts.

When other conventional risk factors for CVD were analyzed in our cohorts, blood pressure, total cholesterol, LDL, triglycerides, triglyceride-to-HDL ratio, and family history of CVD did not correlate with CIMT within the $\mathrm{CAH}$ group. Our findings that CIMT did not correlate

Carotid Wall Thickness and Androgens in $\mathrm{CAH}$ with lipid levels (with the exception of HDL) are similar to a previous investigation in classical CAH patients [14], although the results of both studies are in contrast to associations noted between CIMT, triglycerides, and triglyceride-to-HDL ratio in a cohort that included both classical and nonclassical CAH patients [13]. However, our finding that HDL was inversely correlated with CIMT in both the $\mathrm{CAH}$ and control groups is consistent with normative CIMT studies in adolescents with and without obesity [35], and reports that suggest a protective effect of HDL on CVD risk $[36,37]$. It is well known that HDL promotes reverse cholesterol transport by inducing macrophages to carry cholesterol out of the artery wall [3638 ] and thereby may protect against the development of atherosclerotic changes in the carotid intima media.

There are several limitations to our study. Our findings are limited by the relatively small cohort size compared to normative data samples. Additional studies with a larger sample size and longer-term follow-up would increase statistical power to compare outcomes with CIMT in adolescents and young adults with $\mathrm{CAH}$, especially for subgroup analyses within the CAH cohort. However, two previous studies in $\mathrm{CAH}$ adolescents and young adults showed CIMT increases in CAH using comparable sample sizes of 18-19 individuals $[9,13]$, implying that these sample sizes have sufficient power for between-group analyses. Relative to these previously published effects, our study possesses a power of $>99 \%$. A second limitation of our study is the ethnicity of our study population, which was $70 \%$ Hispanic. The generalizability of our findings to patient populations of non-Hispanic ethnicity may be limited, given that previous studies have shown ethnicity to be an independent predictor of arterial wall thickness [39]. Conversely, the predominance of Hispanic subjects in our study could be viewed as a strength, reducing the confounding effect of interethnic variability on CIMT. Further studies are needed to determine the effect of ethnicity on CIMT in individuals with CAH. Although most CAH subjects in our study were not in acceptable hormonal control, as assessed by their early morning 17-OHP level, this degree of control is similar to that of a large cohort of CAH patients reported to have approximately $30 \%$ of patients in acceptable control [6]. Our study is also limited by its cross-sectional design, and can thus only identify associations but not determine causation.

Our study adds to the literature investigating subclinical atherosclerosis risk in adolescents and young adults with $\mathrm{CAH}$, which has included varied associations between CIMT, lipids and adrenal androgens, as well as varied observations in CIMT differences between CAH sub- 
jects and controls [12-14]. These variations between studies may be due to differences in measures such as timing of adrenal androgen measurements in relation to the morning glucocorticoid dose, wavelength of ultrasound transducer, and study design with regard to the cohort. Our study shows that male sex, obesity, 17-OHP, androstenedione, and advanced BA positively correlate with increased CIMT, while HDL inversely correlates with CIMT. Our findings suggest that hyperandrogenism is also associated with increased CIMT after controlling for obesity, which is consistent with studies in hyperandrogenic women with PCOS $[40,41]$. Particularly noteworthy is that both females and males with $\mathrm{CAH}$ and advanced $\mathrm{BA}$, presumably reflecting prolonged hyperandrogenism, demonstrate correlations with increased CIMT. Our study suggests that hyperandrogenism in $\mathrm{CAH}$ is linked to increased CVD risk of subclinical atherosclerosis, independent of obesity, and that there is a potential synergistic risk of having both obesity and hyperandrogenism in patients with CAH. Given the risk for obesity, hypertension, insulin resistance, and vascular dysfunction in $\mathrm{CAH}$ youth, along with multiple CVD risk factors in CAH adults $[6,42,43]$, further studies in CAH adolescents and young adults need to be done to assess measures of hyperandrogenism and CIMT over time. The rate of CVD events among adults with CAH is beginning to be characterized [43]. The association between CIMT progression, hormone imbalances, and medications specific to $\mathrm{CAH}$, and CVD events, will be important to characterize in this at-risk cohort. Our results highlight the importance of maintaining good hormonal control, a healthy weight and active lifestyle, and monitoring lipid levels to prevent the development of CVD in patients with CAH.

\section{Acknowledgments}

We gratefully thank our patients and their families for their participation. This work was supported by Southern California Clinical and Translational Science Institute (NIH/NCRR/NCATS) Grant KL2TR000131 (to M.S.K.), Children's Hospital Los Angeles Clinical and Translational Science Institute Clinical Trials Unit Grant 1UL1RR031986 (to M.S.K.), and The Abell Foundation (to M.E.G.). Its contents are solely the responsibility of the authors and do not necessarily represent the official views of the NIH. We also thank Norma Castaneda, Sheela Rao, Christina Reh, the Children's Hospital Los Angeles Clinical Trials Unit, and the Children's Hospital Los Angeles Children's Imaging Research Program for their assistance and support.

\section{References}

1 Bots ML, Hoes AW, Koudstaal PJ, Hofman A, Grobbee DE: Common carotid intima-media thickness and risk of stroke and myocardial infarction: the Rotterdam Study. Circulation 1997;96:1432-1437.

2 The Atherosclerosis Risk in Communities (ARIC) Study: design and objectives. The ARIC investigators. Am J Epidemiol 1989; 129:687-702.

-3 Mittelman SD, Gilsanz P, Mo AO, Wood J, Dorey F, Gilsanz V: Adiposity predicts carotid intima-media thickness in healthy children and adolescents. J Pediatr 2010;156:592-597.

-4 Zhao G, Ford ES, Li C, Tsai J, Dhingra S, Balluz LS: Waist circumference, abdominal obesity, and depression among overweight and obese US adults: National Health and Nutrition Examination Survey 2005-2006. BMC Psychiatry 2011;11:130.

5 Volkl TM, Simm D, Beier C, Dorr HG: Obesity among children and adolescents with classic congenital adrenal hyperplasia due to 21-hydroxylase deficiency. Pediatrics 2006; 117:e98-e105.

6 Finkielstain GP, Kim MS, Sinaii N, Nishitani M, Van Ryzin C, Hill SC, Reynolds JC, Hanna RM, Merke DP: Clinical characteristics of a cohort of 244 patients with congenital adrenal hyperplasia. J Clin Endocrinol Metab 2012; 97:4429-4438.

7 Cornean RE, Hindmarsh PC, Brook CG: Obesity in 21-hydroxylase deficient patients. Arch Dis Child 1998;78:261-263.

-8 Subbarayan A, Dattani MT, Peteres CJ, Hindmarsh PC: Cardiovascular risk factors in children and adolescents with congenital adrenal hyperplasia due to 21 -hydroxylase deficiency. Clin Endocrinol 2014;80:471-477.

-9 Sartorato P, Zulian E, Benedini S, Mariniello B, Schiai F, Bilora F, Pozzan G, Greggio N, Pagnan A, Mantero F, Scaroni C: Cardiovascular risk factors and ultrasound evaluation of intima-media thickness at common carotids, carotid bulbs, and femoral and abdominal aorta arteries in patients with classic congenital adrenal hyperplasia due to 21-hydroxylase deficiency. J Clin Endocrinol Metab 2007;92: 1015-1018.

10 Conway G, Dewailly D, Diamanti-Kandarakis E, Escobar-Morreale HF, Franks S, Gambineri A, Kelestimur F, Macut D, Micic D, Pasquali R, Pfeifer M, Pignatelli D, Pugeat M, Yildiz BO: The polycystic ovary syndrome: a position statement from the European Society of Endocrinology. Eur J Endocrinol 2014;171: $1-29$.
1 Meyer ML, Malek AM, Wild RA, Korytkowski MT, Talbott EO: Carotid artery intima-media thickness in polycystic ovary syndrome: a systematic review and metaanalysis. Hum Reprod Update 2012;18:112126.

12 Harrington J, Pena AS, Gent R, Hirte C, Couper J: Adolescents with congenital adrenal hyperplasia because of 21-hydroxylase deficiency have vascular dysfunction. Clin Endocrinol 2012;76:837-842.

13 Wasniewska M, Balsamo A, Valenzise M, Manganaro A, Faggioli G, Bombaci S, Conti V, Ferri M, Aversa T, Cicognani A, De Luca F: Increased large artery intima media thickness in adolescents with either classical or non-classical congenital adrenal hyperplasia. J Endocrinol Invest 2013;36:12-15.

14 Amr NH, Ahmed AY, Ibrahim YA: Carotid intima media thickness and other cardiovascular risk factors in children with congenital adrenal hyperplasia. J Endocrinol Invest 2014; 37:1001-1008.

15 Falkner B: The Fourth Report on the Diagnosis, Evaluation, and Treatment of High Blood Pressure in Children and Adolescents. Bethesda, National Heart Lung and Blood Institute, 2005, pp 1-48. 
16 Chobanian A: The Seventh Report of the Joint National Committee on Prevention, Detection, Evaluation, and Treatment of High Blood Pressure. Bethesda, National Heart Lung and Blood Institute, 2004, pp 1-86.

17 McDowell MA, Fryar CD, Ogden CL: Anthropometric reference data for children and adults: United States, 1988-1994. Vital Health Stat 2009;249:1-68.

18 Gonzalez J, Wood JC, Dorey FJ, Wren TA, Gilsanz V: Reproducibility of carotid intimamedia thickness measurements in young adults. Radiology 2008;247:265-271.

19 Greulich WW, Pyle SI: Radiographic Atlas of Skeletal Development of the Hand and Wrist, ed 2. Stanford, Stanford University Press, 1959.

20 Faul F, Erdfelder E, Buchner A, Lang AG: Statistical power analysis using $\mathrm{G}^{*}$ Power 3.1 : tests for correlation and regression analyses. Behav Res Methods 2009;41:1149-1160.

$\checkmark 21$ Kim MS, Merke DP: Cardiovascular disease risk in adult women with congenital adrenal hyperplasia due to 21-hydroxylase deficiency. Semin Reprod Med 2009;27:316-321.

22 Mendis S, Puska P, Norrving B (eds): Global Atlas on Cardiovascular Disease Prevention and Control. Geneva, World Health Organization, World Heart Federation, and World Stroke Organization, 2011.

23 Jones TH, Saad S: The effects of testosterone on risk factors for, and the mediators of, the atherosclerotic process. Atherosclerosis 2009; 207:318-327.

24 Kanayama G, Pope HG Jr: Illicit use of androgens and other hormones: recent advances. Curr Opin Endocrinol Diabetes Obes 2012, 19:211-219.

25 Wild RA, Applebaum-Bowden D, Demers LM, Bartholomew M, Landis JR, Hazzard WR, Santen RJ: Lipoprotein lipids in women with androgen excess: independent associations with increased insulin and androgen. Clin Chem 1990;36:283-289.

-26 Dokras A: Cardiovascular disease risk factors in polycystic ovary syndrome. Semin Reprod Med 2008;26:39-44.

27 Macut D, Bacevic M, Bozic-Antic I, BjekicMacut J, Civcic M, Erceg S, Milutinovic DV, Stanojlovic O, Andric Z, Kastratovic-Kotlica B, Sukilovic T: Predictors of subclinical cardiovascular disease in women with polycystic ovary syndrome: interrelationship of dyslipidemia and arterial blood pressure. Int J Endocrinol 2015;2015:812610.

28 Huppert J, Chiodi M, Hillard PJ: Clinical and metabolic findings in adolescent females with hyperandrogenism. J Pediatr Adolesc Gynecol 2004;17:103-108.

29 Golden SH, Ding J, Szklo M, Schmidt MI, Duncan BB, Dobs A: Glucose and insulin components of the metabolic syndrome are associated with hyperandrogenism in post menopausal women: the atherosclerosis risk in communities study. Am J Epidemiol 2004; 160:540-548.

30 Wang L, Szklo M, Folsom AR, Cook NR, Gapstur SM, Ouyang P: Endogenous sex hormones, blood pressure change, and risk of hypertension in postmenopausal women: the Multi-Ethnic Study of Atherosclerosis. Atherosclerosis 2012;224:228-234.

31 Mäki-Petäjä KM, Wilkinson IB: Inflammation and large arteries: potential mechanisms for inflammation-induced arterial stiffness potential mechanisms for inflammation-induced arterial stiffness. Artery Res 2012;6:5964.

32 Costa TJ, Ceravolo GS, dos Santos RA, de Oliveira MA, Araujo PX, Giaguinto LR, Tostes RC, Akamine EH, Fertes ZB, Dantas $\mathrm{AP}$, Carvalho MH: Association of testosterone with estrogen abolishes the beneficial effect of estrogen treatment by increasing ROS generation in aorta endothelial cells. Am J Physiol Heart Circ Physiol 2015;308:H723H732.

33 Labruijere S, van Houten ELAF, de Vries R, Musterd-Bagghoe US, Garrelds IM, Kramer P, Danser AHJ, Villalon CM, Visser JA, Van Den Brink AM: Analysis of the vascular responses in a murine model of polycystic ovary syndrome. J Endocrinol 2013;218:205-213.

- 34 Kim MS, Ryabets-Lienhard A, Dao-Tran A, Mittelman SD, Gilsanz V, Schrager SM, Geffner ME: Increased abdominal adiposity in adolescents and young adults with congenital adrenal hyperplasia due to 21-hydroxylase deficiency. J Clin Endocrinol Metab 2015; 100:E1153-E1159.

35 Bekdas M, Kaya E, Dagistan E, Goksugur SB, Demircioglu F, Erkocoglu M, Dilek M: The association of obesity and obesity-related conditions with carotid extra-medial thickness in children and adolescents. Pediatr Obes 2015, Epub ahead of print.

-36 Khera AV, Cuchel M, de la Llera-Moya M, Rodrigues A, Burke MF, Jafri K, French BC, Phillips JA, Mucksavage ML, Wilensky RL, Mohler ER, Rothblat GH, Rader DJ: Cholesterol efflux capacity, high-density lipoprotein function, and atherosclerosis. N Engl J Med 2011;364:127-135.

37 Okumura K, Tsukamoto H, Tsuboi H, Hirayama $H$, Kamiya $H$, Watarai $M$, Ishiki $R$, Murohara T: High HDL cholesterol level after treatment with pitavastatin is an important factor for regression in carotid intima-media thickness. Heart Vessels 2015;30:154-161.

38 Von Eckardstein A, Rohrer L: Transendothelial lipoprotein transport and regulation of endothelial permeability and integrity by lipoproteins. Curr Opin Lipidol 2009;20:197205.

39 Breton CV, Wang X, Mack WJ, Berhane K, Lopez M, Islam TS, Feng M, Hodis HN, Künzli N, Avol E: Carotid artery intima-media thickness in college students: race/ethnicity matters. Atherosclerosis 2011;217:441-446.

40 Sprung VS, Atkinson G, Cuthbertson DJ, Pugh CJA, Aziz N, Green DJ, Cable NT, Jones $\mathrm{H}$ : Endothelial function measured using flowmediated dilation in polycystic ovary syndrome: a meta-analysis of the observational studies. Clin Endocrinol 2013;78:438-446.

41 Paradisi G, Steinberg HO, Hempfling A, Cronin J, Hook G, Shepard MK, Baron AD: Polycystic ovary syndrome is associated with endothelial dysfunction. Circulation 2001;103: 1410-1415.

42 Arlt W, Willis DS, Wild SH, Krone N, Doherty EJ, Hahner S, Han TS, Carroll PV, Conway GS, Rees DA, Stimson RH, Walker BR, Connell JM, Ross RJ: Health status of adults with congenital adrenal hyperplasia: a cohort study of 203 patients. J Clin Endocrinol Metab 2010; 95:5110-5121.

43 Falhammar H, Frisen L, Linden Hirschberg A, Norrby C, Almqvist C, Nordenskjold A, Nordenstrom A: Increased cardiovascular and metabolic morbidity in patients with 21-hydroxylase deficiency: a Swedish population-based national cohort study. J Clin Endocrinol Metab 2015;100:3520-3528. 